\title{
Influence of season on seminal characteristics, testis size and serum testosterone in the western spotted skunk (Spilogale gracilis)
}

\author{
J. B. Kaplan and R. A. Mead \\ Department of Biological Sciences, University of Idaho, Moscow, ID 83843, USA
}

\begin{abstract}
The western spotted skunk is a seasonally breeding mammal: most copulations occur in late September and early October. This study was performed to characterize the seasonal changes in concentrations of testosterone and in ejaculate quality. Captive males $(n=22)$ were maintained on a natural photoperiod for 15 months. Semen samples were collected by electroejaculation; testis size was measured; and blood samples were collected. Of 110 electroejaculation attempts, $104(95 \%)$ resulted in successful fluid collection and 101 (97\%) samples contained spermatozoa. Significant increases $(P<0.05)$ in serum testosterone concentration, testis size and ejaculate volume were observed from August to November. Mean concentration of testosterone in serum ranged from $0.15 \pm 0.05 \mathrm{ng} \mathrm{ml}^{-1}$ in mid-January to $6.42 \pm 1.79 \mathrm{ng} \mathrm{ml}^{-1}$ in early October. Mean testis size ranged from $1.22 \pm 0.25 \mathrm{~cm}^{2}$ in February to $2.68 \pm 0.08 \mathrm{~cm}^{2}$ in October. Mean ejaculate volume ranged from $11 \pm 3 \mu \mathrm{lin}$ March to $129 \pm 22 \mu \mathrm{l}$ in October. Seasonal changes in the number of spermatozoa per ejaculate or motility of spermatozoa were not observed. Mean number of spermatozoa per ejaculate was $8.14 \pm 0.85 \times 10^{6}$ spermatozoa $(n=97)$; motility was $56 \pm 2.4 \%(n=93)$; semen $\mathrm{pH}$ was $7.76 \pm 0.20(n=6)$; osmolarity was $394 \pm 13 \mathrm{mmol} \mathrm{kg}^{-1}(n=10)$; and $70.3 \pm 1.5 \%$ of the spermatozoa were morphologically normal $(n=47)$. Concentration of testosterone in serum was highly correlated with testis size $(r=0.484, P<0.001$, $n=137$ ), but none of the semen characteristics was found to be correlated with either concentration of testosterone in serum or testis size $(P>0.05)$. These data suggest that concentration of testosterone in serum, testis size and ejaculate volume increase seasonally as photoperiod decreases.
\end{abstract}

\section{Introduction}

The western spotted skunk, Spilogale gracilis, is a seasonally breeding mammal; the testes reach maximal weight and most copulations occur in late September and early October (Mead, 1968a). Testicular recrudescence occurs from July to October in skunks maintained on a natural photoperiod (Berria et al., 1990) and the pineal gland is considered to be involved in entraining this testicular cycle. Other attributes of the male reproductive cycle, such as seminal characteristics and testosterone concentrations, have not been reported for this species.

Electroejaculation has been used successfully to obtain semen from a few mustelid carnivores including domestic ferrets, Mustela putorius (Shump et al., 1976; Atherton et al, 1989; Wildt et al., 1989), black-footed ferrets, Mustela nigripes (Kitchin et al., 1988; Curry et al., 1989), and mink, Mustela vison (Aulerich et al., 1972). To our knowledge, seasonal profiles of seminal characteristics have not been described in other mustelids. However, concentrations of testosterone in serum have been reported to exhibit seasonal variation in domestic ferrets (Neal et al., 1977; Boissin-Agasse and Boissin, 1979), mink (BoissinAgasse and Boissin, 1979), European pine martens, Martes martes and stone-martens, Martes foina (Audy, 1976), wolverines, Gulo

Received 18 May 1992 gulo (Mead et al., 1991), river otters, Lutra canadensis (Stenson, 1985), stoats, Mustela erminea (Gulamhusein and Tam, 1974), and European badgers, Meles meles (Maurel et al., 1984).

Knowledge of the characteristics of the normal reproductive cycle of male western spotted skunks and development of a successful means by which to obtain this information are critical to studies of the control of the reproductive cycle in males and to captive propagation of this species. The objectives of this study were to determine the success rate of electroejaculation in the western spotted skunk, to characterize the seasonal changes in ejaculate quality, testis size, and testosterone concentrations, and to determine whether ejaculate characteristics varied as a function of testis size or testosterone concentration.

\section{Materials and Methods}

Animals

Eighteen male western spotted skunks (Spilogale gracilis latifrons) weighing $619 \pm 62 \mathrm{~g}$ were obtained from a trapper in Oregon, and six additional males were born in the laboratory to pregnant females caught in the wild from the same area. All skunks were maintained in a windowless room. The light-dark cycle was controlled by a Tork Model $7122 Z$ light timer (Tork Inc., Mt Vernon, NY) that was set to simulate precisely the 
seasonal changes in photoperiod at our latitude of $46^{\circ} 43^{\prime} 57^{\prime \prime} \mathrm{N}$ by daily variations in the light period. All animals were individually housed and were provided with Purina Ferret Chow and water ad libitum.

\section{Testicular size}

Animals were sedated with ketamine $\left(40 \mathrm{mg} \mathrm{kg}^{-1}\right.$, i.m.; Ketaset: Fort Dodge Laboratories, Fort Dodge, IA) no more than once per week for 15 months when measuring the length and width of the right testis through the scrotum with calipers.

\section{Seminal characteristics}

Semen was collected no more than once per week by electroejaculation from skunks sedated with ketamine (40 $\mathrm{mg} \mathrm{kg}^{-1}$ ) using an AC Nicholson stimulator (Nicholson Mfg., Denver, CO). A $0.95 \mathrm{~cm}$ diameter bipolar electrode (Healey and Sadleir, 1966) coated with H-R Jelly (Youngs Drug Products Corp., Piscataway, NJ) was inserted into the rectum to a depth of approximately $4 \mathrm{~cm}$. Thirty 3 volt stimuli were applied for approximately $4 \mathrm{~s}$ each with about $4 \mathrm{~s}$ between successive stimuli. This procedure was repeated at 4, 6 and 9 volts. Five 6 volt stimuli were then applied for approximately $4 \mathrm{~s}$ each with about $4 \mathrm{~s}$ between successive stimuli. This procedure was repeated at 4 and 3 volts. The ejaculate was collected into and volume measured in $50 \mu \mathrm{l}$ glass micropipettes (Sigma Chemical Co., St Louis, MO) calibrated at $5 \mu$ intervals. This micropipette was placed directly on the urethral opening of the penis and seminal plasma was collected by capillary action. The semen was immediately diluted $(1: 2 \mathrm{v} / \mathrm{v}$ semen to extender) in TEST medium, consisting of $20 \%(\mathrm{v} / \mathrm{v})$ egg yolk, $0.4 \%(\mathrm{w} / \mathrm{v}) \mathrm{D}$-glucose (Sigma), 4.83\% (w/v) Tes (Sigma), 1.05\% $(\mathrm{w} / \mathrm{v}) \mathrm{Tris}-\mathrm{HCl}$ (Sigma), 0.1\% (w/v) Tris base (Sigma), 746 units penicillin-G potassium salt $\mathrm{ml}^{-1}$ (Sigma), and 563 units streptomycin sulfate $\mathrm{ml}^{-1}$ (Sigma). The semen-free extender was centrifuged at $3000 \mathrm{~g}$ for $20 \mathrm{~min}$ to remove high-density yolk particles before use to improve visibility of spermatozoa. A subjective estimate of the percentage of spermatozoa that were motile on a pre-warmed glass slide, examined at room temperature, was recorded. The number of spermatozoa ml ${ }^{-1}$ of ejaculate was determined using a haemocytometer, and the total number of spermatozoa calculated by multiplying the concentration by the ejaculate volume. The percentage of sperm abnormalities was documented from July to December by light microscopy $(\times 400)$, by examining the first 200 spermatozoa encountered in dilute samples of freshly collected semen and classifying the abnormalities observed according to Wildt $e t$ al. (1983). Several undiluted samples collected in late November and early December were used to measure seminal $\mathrm{pH}$, using a micro $\mathrm{pH}$ electrode (Lazar, Los Angeles, CA) and osmolarity, using a vapour pressure osmometer (Wescor Model 5100C, Logan, UT).

\section{Testosterone assay}

Biweekly blood samples were obtained (between 14:00 and 16:00 h) via cardiac puncture under ketamine anaesthesia; the samples were allowed to clot and centrifuged at $1050 \mathrm{~g}$ for $20 \mathrm{~min}$; the serum was stored at $-20^{\circ} \mathrm{C}$ until the time of assay. Testosterone concentrations in the serum were determined in a single assay using a solid phase radioimmunoassay kit (Diagnostic Products Corporation, Los Angeles, CA). The antiserum was reported by the manufacturer to have less than $3.5 \%$ crossreactivity with dihydrotestosterone and less than $2 \%$ crossreactivity with 30 other steroids. When testosterone (Sigma) was added to plasma from castrated skunks at concentrations of $1-15 \mathrm{ng} \mathrm{ml}^{-1}$, the amount of testosterone added and that recovered were highly positively correlated $(r=0.997)$. Displacement curves of skunk plasma dilutions were parallel to the standard curve. Sensitivity of the assay, defined as the concentration at $95 \% \mathrm{~B}: \mathrm{B}_{\mathrm{o}}$, was determined by the manufacturer to be $0.04 \mathrm{ng} \mathrm{ml}^{-1}$. The intra-assay coefficient of variation, defined as the mean coefficient of variation of all duplicates, was $4.54 \pm 0.28 \%(n=234)$.

\section{Statistical analysis}

Concentrations of testosterone in serum, testis size, and data regarding seminal characteristics were analysed using analysis of variance to determine the sources of variation in mean values of these traits. This was followed by individual pairwise comparisons using Fisher's least significant difference (LSD) test to determine which of the individual mean values were significantly different at different times of the year. Pearson's correlation coefficients were determined for the relationships between concentrations of testosterone, testis size and each of the seminal characteristics. Differences between means and correlations were considered significant when $P$ was $<0.05$.

\section{Results}

\section{Seasonal changes in testosterone concentration and testis size}

A seasonal pattern was observed in mean concentrations of testosterone in serum (Fig. 1a), which ranged from a low of $0.15 \pm 0.05 \mathrm{ng} \mathrm{ml}^{-1}$ in mid-January to a peak of $6.42 \pm 1.79 \mathrm{ng} \mathrm{ml}^{-1}$ in early October. Increasing testosterone concentrations were observed from February to early May, when the mean concentration reached $2.40 \pm 0.65 \mathrm{ng} \mathrm{ml}^{-1}$ and was not significantly different $(P>0.05)$ from the large peak in October. Concentration of testosterone then decreased again until the major seasonal rise began at the end of July. After the October peak, the concentration of testosterone decreased rapidly until mid-November. Mean concentrations of testosterone were comparable at similar sampling dates over the two years from October to December.

Mean testis size, expressed as the product of length $\times$ width, also exhibited seasonal changes (Fig. 1b), ranging from $1.22 \pm 0.25 \mathrm{~cm}^{2}$ in February to $2.68 \pm 0.08 \mathrm{~cm}^{2}$ in October. A small increase in testis size occurred with a peak of $1.82 \pm 0.18 \mathrm{~cm}^{2}$ in April, and then decreased until the major rise from August to October. In both years, mean testis size decreased in November and December. Furthermore, testis size exhibited a positive correlation $(P<0.001, r=0.484, n=137)$ with testosterone concentration. 

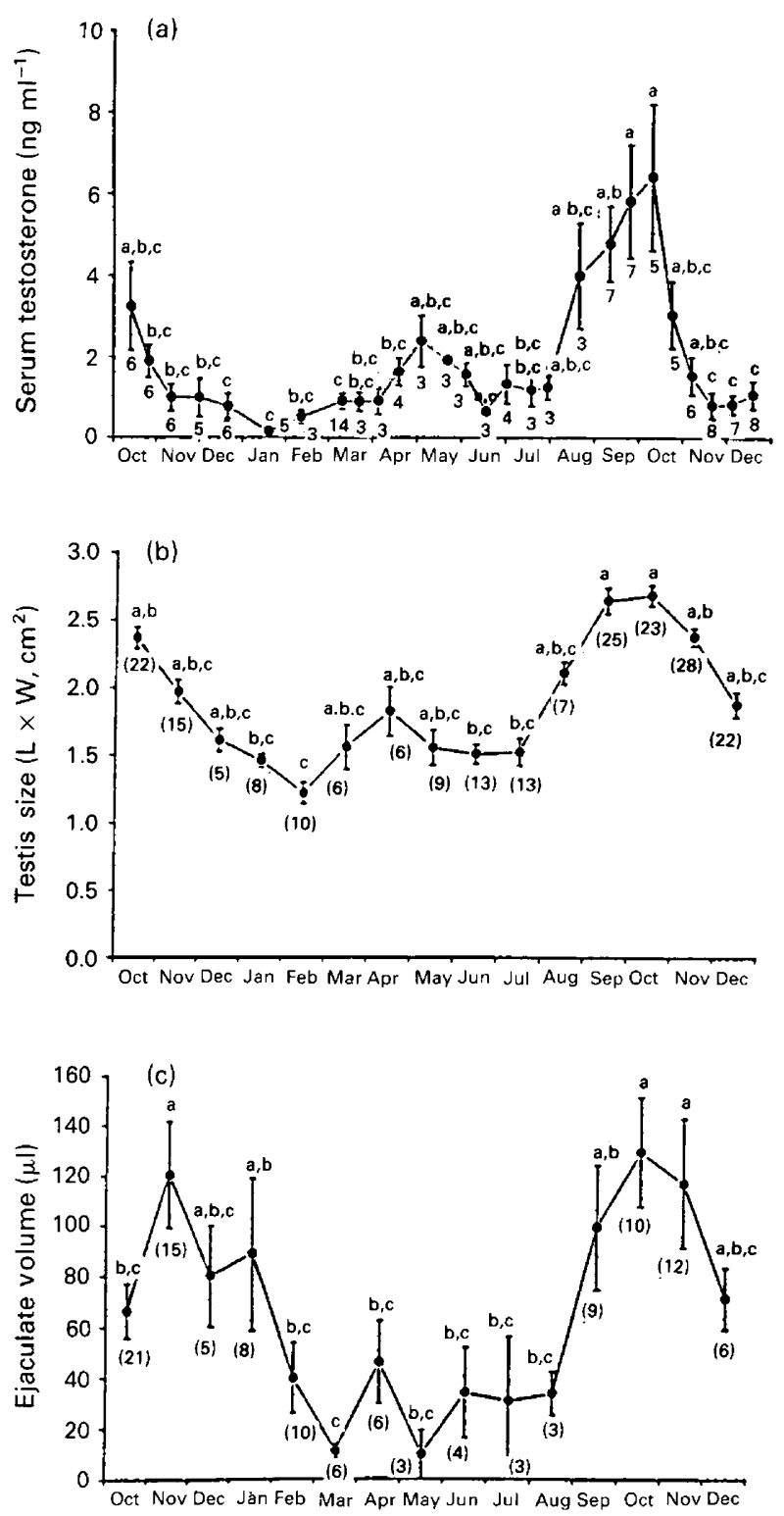

Fig. 1. Seasonal pattern of (a) concentration of testosterone in serum, (b) testis size (length $\times$ width), and (c) ejaculate volume over 15 months in skunks exposed to a natural photoperiod. Values are means \pm SEM. The number of animals sampled at each date is shown below the standard error bar or the sample sizes per month are in parentheses. Means with different letters above the standard error bar are significantly different $(P<0.05)$ using Fisher's LSD.

\section{Seminal characteristics}

Of 110 electroejaculation attempts, $104(95 \%)$ resulted in successful seminal plasma collection and $101(97 \%)$ of 104 samples contained spermatozoa. The mean volume of these ejaculates exhibited seasonal variation (Fig. Ic), with a nadir of $11 \pm 3 \mu \mathrm{l}$ in March to a peak of $129 \pm 22 \mu \mathrm{l}$ in October. A slight secondary increase was observed in April, when the mean ejaculate volume was $46 \pm 16 \mu \mathrm{l}$. The mean volume of ejaculate increased and remained high from September to November. Although ejaculate volume was not significantly correlated with concentration of testosterone in serum $(P>0.05, r=0.038$, $n=80)$ or testis size $(P>0.05, r=0.166, n=80)$, it did follow the same seasonal pattern as these variables.

Seasonal changes were not detected in the number of spermatozoa per ejaculate, or in concentration or motility of spermatozoa. The mean number of spermatozoa per ejaculate was $8.14 \pm 0.85 \times 10^{6}$ spermatozoa $(n=97)$; the concentration of spermatozoa was $1.32 \pm 0.16 \times 10^{8}$ spermatozoa $\mathrm{ml}^{-1}(n=97)$, motility was $56 \pm 2.4 \% \quad(n=93)$, and $70.3 \pm 1.5 \%$ of the spermatozoa were morphologically normal $(n=47)$. Mean monthly values for these characteristics of the semen are shown (Table 1). Semen pH was $7.76 \pm 0.20(n=6)$ and osmolarity was $394 \pm 13 \mathrm{mmol} \mathrm{kg}^{-1}(n=10)$. A categorization of the mean percentages of spermatozoa with specific morphological defects is shown (Table 2). The prevalence of the various morphological abnormalities did not vary widely over the six months sampled; the coiled tail was consistently the most common defect. None of the seminal characteristics was found to be significantly correlated with either serum testosterone concentration or testis size $(P>0.05)$.

\section{Discussion}

Testicular function in western spotted skunks exhibits seasonal variation. The seasonal changes in testis size reported in this study agree with previous results in this species (Mead, 1968a; Berria et al., 1990), the greatest testis size being observed during the autumn breeding season. The peak in mean testis size was approximately twice the basal size. Mean paired testis weights vary seasonally between 617 and $1408 \mathrm{mg}$ (Mead, 1968a). This is similar to the proportional size change seen in mink (Lundh, 1961; Onstad, 1967; Boissin-Agasse and Boissin, 1979), European badgers (Audy-Relexans, 1972; Maurel et al., 1984), wolverines (Mead et al., 1991), and river otters (Stenson, 1985). However, a much greater change in testis size occurs in least weasels, Mustela nivalis (Hill, 1939), polecats, Mustela eversmanni (Mead et al., 1990), American badgers, Taxidea taxus (Wright, 1969), ferrets (Allanson, 1932; Boissin-Agasse and Boissin, 1979), European pine martens and stone-martens (Audy, 1976) and stoats (Gulamhusein and Tam, 1974).

Concentrations of testosterone in serum of the western spotted skunk were greatest during the autumn breeding season and exhibited a high positive correlation with testis size. The concentrations fall within the range reported for mink (BoissinAgasse and Boissin, 1979; Sundqvist et al., 1984), European badgers (Audy and Bonnin-Laffargue, 1975; Audy, 1976; Maurel et al., 1984), European pine and stone-martens (Audy, 1976, 1978), wolverines (Mead et al., 1991), and river otters (Stenson, 1985), but are significantly higher during the breeding season in domestic ferrets (Neal et al., 1977; Boissin-Agasse and Boissin, 1979; Sisk and Desjardins, 1986) and stoats (Gulamhusein and Tam, 1974). All of the above male mustelids exhibit increased testosterone concentrations and testis size prior to the breeding season for their species.

The pattern of seasonal changes in serum testosterone concentrations and testis size in the western spotted skunk differs from that of most other mustelids. A distinct rise and fall in testis size and concentrations of testosterone occurs in April and early May and precedes the major changes in testis size and 


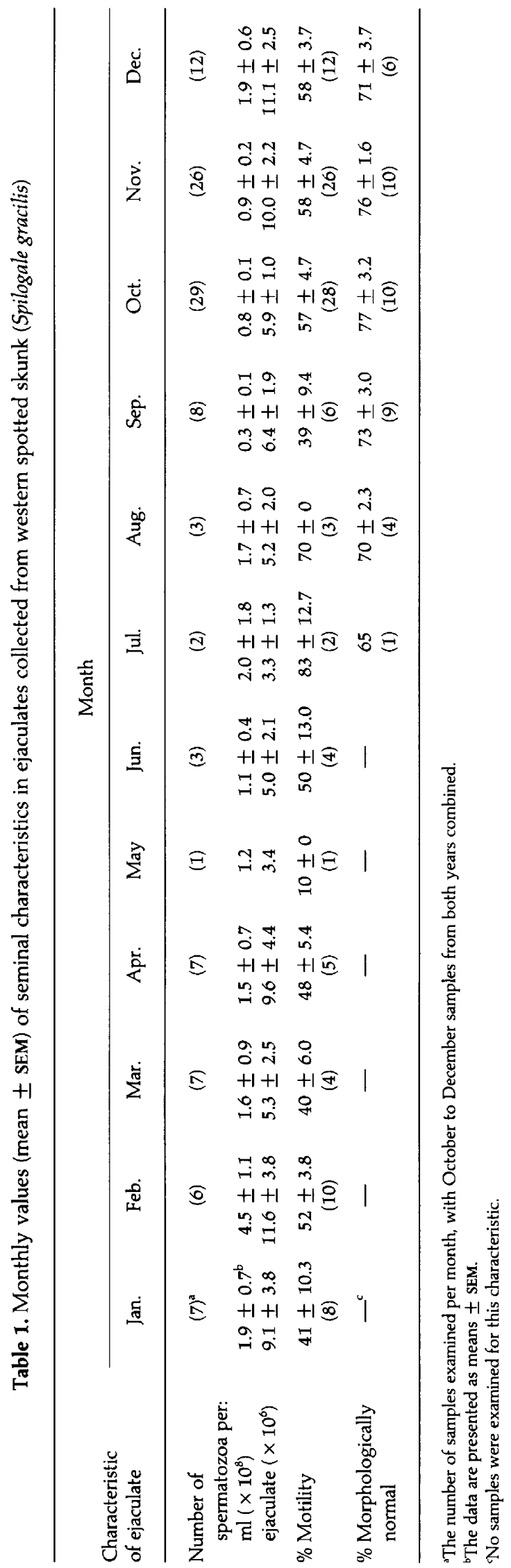


Table 2. Mean \pm SEM percentages of 200 spermatozoa per ejaculate that exhibited specific morphological abnormalities in 47 samples collected from western spotted skunk by electroejaculation

\begin{tabular}{ll} 
Morphological defect & Mean \pm SEM \\
\hline $\begin{array}{l}\text { Primary abnormalities } \\
\text { Large head }\end{array}$ & \\
Small head & $0.01 \pm 0.01 \%$ \\
Coiled tail & $0.05 \pm 0.02 \%$ \\
Secondary abnormalities & $15.2 \pm 1.2 \%$ \\
$\quad$ Bent tail tip & \\
Bent tail & $2.8 \pm 0.3 \%$ \\
Bent midpiece & $3.1 \pm 0.7 \%$ \\
Protoplasmic droplet & $4.0 \pm 0.5 \%$ \\
\end{tabular}

secretory activity, which peak in early October. The autumn breeding season of the western spotted skunk is followed by a prolonged period of delayed implantation of the embryos. It has been suggested that embryonic diapause in this species is a specialized condition that has evolved from a spring breeding and short gestation reproductive pattern (Mead, 1989). The April-May testosterone peak in the male skunk may represent a remnant of this former spring breeding season. Eastern spotted skunks (S. putorius) breed in the spring and do not exhibit a delay of implantation (Mead, 1968b). One of its subspecies (S. p. ambarvilus) exhibits peak testis size and concentration of testosterone at the same time as the truncated spring peak observed in western spotted skunks (Kaplan, 1992). A second testosterone peak has also been observed in stoats (Gulamhusein and Tam, 1974), stone-martens (Audy, 1978), wolverines (Mead et al., 1991) and ferrets (Boissin-Agasse and Boissin, 1979).

Electroejaculation proved to be an extremely successful method of semen collection in western spotted skunks. The success rate of semen collection in skunks exceeds that obtained in mink (Aulerich et al., 1972) and domestic ferrets (Shump et al., 1976; Wildt et al., 1989). The low volume of seminal plasma obtained by electroejaculation is presumably attributable to the fact that the prostate is the only accessory sex gland in skunks (Mead, 1970). Ejaculate volume varied seasonally in skunks, corresponding to the variation in testis size, concentrations of testosterone in serum, and the breeding season. Surprisingly, our lowest mean ejaculate volume was comparable to mean breeding season volumes in ferrets (Shump et al., 1976; Atherton et al., 1989) and mink (Aulerich et al., 1972). Spermatogenesis has been reported to occur throughout the year in European badgers (Audy-Relexans, 1972; Audy and Bonnin-Laffargue, 1975). Skunk semen samples containing spermatozoa were obtained in every month of the year in this study. Mead (1966) reported a complete absence of spermatozoa in both the testes and epididymides in most wild caught western spotted skunks collected in January $(n=22)$ and February $(n=9)$ and in all three animals collected in March. Testes of some juveniles of this species are devoid of spermatids or spermatozoa during their first breeding season (Mead 1968a), so it is possible that the individuals in their March sample had not yet initiated their first testicular cycle. Another possible explanation for these seemingly divergent results is that the diet of our captive skunks was very rich compared with that obtained in the wild during the winter. This nutritional augmentation may have affected testicular or epididymal physiology.

The concentration and motility of spermatozoa in the skunk ejaculate, which did not exhibit seasonal variation or correlate with testis size or testosterone concentration, was near mean values observed in domestic ferrets (Shump et al., 1976) and mink (Aulerich et al., 1972). Our failure to detect seasonal changes in sperm concentration is presumably attributable to the high degree of variation observed among samples.

The percentage of morphologically defective spermatozoa remained constant throughout the six months examined in this study. Mean percentages of normal spermatozoa have been observed to be significantly lower in domestic and black-footed ferrets (Curry et al., 1989). It has been suggested that the low percentages of morphologically normal spermatozoa in the black-footed ferret may be a consequence of inbreeding during a genetic bottleneck in this species or might be due to fixation (Curry et al., 1989). Only fresh unfixed semen samples were examined in skunks.

Our data show that electroejaculation is a highly successful method of semen collection in the western spotted skunk, resulting in semen samples that are similar in their characteristics to those seen in other mustelids. The data are also consistent with the hypothesis that the male spotted skunk exhibits a seasonal breeding season, with concentration of testosterone in serum, testis size, and ejaculate volume reaching peak values by early October.

Some of these data were presented at the 24th Annual Meeting of the Society for the Study of Reproduction, July 1991, Vancouver, BC. We thank T. Judd and W. Berndt for technical assistance with semen collection.

\section{References}

Allanson M (1932) The reproductive processes of certain mammals. III. The reproductive cycle of the male ferret Proceedings of the Royal Society of London, Series B 110 295-312

Atherton RW, Straley M, Curry P, Slaughter R, Burgess W and Kitchin RM (1989) Electroejaculation and cryopreservation of domestic ferret sperm. In Conservation Biology and the Black-Footed Ferret pp 177-189. Eds US Seal, ET Thorne, M Bogen and SH Anderson. Yale University Press, New Haven

Audy MC (1976) Le cycle sexuel saisonnier du mâle des mustélidés Europeens General and Comparative Endocrinology 30 117-127

Audy MC (1978) Variations saisonnières de la testostérone plasmatique chez la Fouine (Martes foina Erx.). Comptes Rendus Academie des Sciences, Paris, Series D $287721-724$

Audy MC and Bonnin-Laffargue M (1975) L'activité endocrine du testicule chez le blaireau Européen (Meles meles L.) Archives de Biology 86 222-232

Audy-Relexans MC (1972) Le cycle sexuel du blaireau mâle (Meles meles L.) Annales de Biologie animale, Biochimie, Biophysique 12 355-366

Aulerich RJ, Ringer RK and Sloan CS (1972) Electro-ejaculation of mink (Mustela vison) Journal of Animal Science 34 230-233

Berria M, DeSantis M and Mead RA (1990) Testicular response to melatonin or suprachiasmatic nuclei ablation in the spotted skunk Journal of Experimental Zoology $25572-79$

Boissin-Agasse L and Boissin J (1979) Variations saisonnières du volume testiculaire et de la testostéronémie chez deux mustélidés: le furet (Mustela furo L.) et le vison (Mustela vison S.) Journal de Physiologie, Paris 75 227-232 
Curry PT, Ziemer T, Van der Horst G, Burgess W, Straley M, Atherton RW and Kitchin RM (1989) A comparison of sperm morphology and silver nitrate staining characteristics in the domestic ferret and the black-footed ferret Gamete Research 22 27-36

Gulamhusein AP and Tam WH (1974) Reproduction in the male stoat, Mustela erminea Journal of Reproduction and Fertility 41 303-312

Healey P and Sadleir RMFS (1966) The construction of rectal electrodes for electro-ejaculation Journal of Reproduction and Fertility 11 299-301

Hill M (1939) The reproductive cycle of the male weasel (Mustela nivalis) Proceedings of the Zoological Society of London (Series B) 109 481-512

Kaplan JB (1992) Characterization of the Reproductive Cycles of Male Eastern and Western Spotted Skunks and Sperm Cryopreservation. MS Thesis, University of Idaho

Kitchin RM, Curry PT, Burgess W, Straley M, Parker M and Atherton RW (1988) Comparison of semen sperm content and sperm motility of European, Siberian, and black-footed ferrets Joumal of Andrology Supplement 940

Lundh E (1961) Testikelutveckling och cykliska förändringar i spermiebildningen hos mink Vara Palsdjur 14 380-384

Maurel D, Lacroix A and Boissin J (1984) Seasonal reproductive endocrine profiles in two wild mammals: the red fox (Vulpes vulpes L.) and the European badger (Meles meles L.) considered as short-day mammals Acta Endocrinologica 105 130-138

Mead RA (1966) Reproduction in the Spotted Skunk (Spilogale putorius). PhD Dissertation, University of Montana

Mead RA (1968a) Reproduction in western forms of the spotted skunk (Genus Spilogale) Journal of Mammalogy 49 373-390

Mead RA (1968b) Reproduction in eastern forms of the spotted skunk (genus Spilogale) Journal of Zoology 156 119-136

Mead RA (1970) The reproductive organs of the male spotted skunk (Spilogale putorius) Anatomical Record 167 291-301

Mead RA (1989) The physiology and evolution of delayed implantation in carnivores. In Carnivore Behavior, Ecology, and Evolution pp 437-464 Ed. JL Gittleman. Cornell University Press, Ithaca
Mead RA, Neirinckx S and Czekala NM (1990) Reproductive cycle of the steppe polecat (Mustela eversmanni) Journal of Reproduction and Fertility $\mathbf{8 8}$ $353-360$

Mead RA, Rector M, Starypan G, Neirinckx S, Jones M and DonCarlos MN (1991) Reproductive biology of captive wolverines Journal of Mammalogy 72 807-814

Neal J, Murphy BD, Moger WH and Oliphant LW (1977) Reproduction in the male ferret: gonadal activity during the annual cycle; recrudescence and maturation Biology of Reproduction 17 380-385

Onstad O (1967) Studies on postnatal testicular changes, semen quality, and anomalies in the mink Acta Endocrinologica Supplement 117 1-117

Shump AU, Aulerich RJ and Ringer RK (1976) Semen volume and sperm concentration in the ferret (Mustela putorius) Laboratory Animal Science 26 913-916

Sisk CL and Desjardins C (1986) Pulsatile release of luteinizing hormone and testosterone in male ferrets Endocrinology 119 1195-1203

Stenson GB (1985) The reproductive cycle of the river otter, Lutra canadensis, in the marine environment of southwest British Columbia. PhD Dissertation, University of British Columbia

Sundqvist C, Lukola A and Valtonen M (1984) Relationship between serum testosterone and fertility in male mink (Mustela vison) Joumal of Reproduction and Fertility 70 409-412

Wildt DE, Bush M, Howard JG, O'Brien SJ, Meltzer D, Van Dyk A, Ebedes $\mathrm{H}$ and Brand DJ (1983) Unique seminal quality in the South African cheetah and a comparative evaluation in the domestic cat Biology of Reproduction 29 1019-1025

Wildt DE, Bush M, Morton C, Morton F and Howard JG (1989) Sperm characteristics and testosterone profiles in ferrets kept in long-day photoperiod, and the influence of hCG timing and sperm dilution medium on pregnancy rate after laparoscopic insemination Journal of Reproduction and Fertility 86 349-358

Wright PL (1969) The reproductive cycle of the male American badger, Taxidea taxus Journal of Reproduction and Fertility Supplement 6 435-445 